\title{
EU Regional Policy: \\ Vertical Fiscal Externalities and Matching Grants*
}

by

\author{
Robert Fenge ${ }^{+}$ \\ ifo Institute, Munich, Germany \\ University of Warwick, Coventry, United Kingdom
}

Matthias Wrede $^{++}$

RWTH Aachen University, Germany

January 2004

* We are grateful to Nobuo Akai, Michael Devereux and Ben Lockwood for helpful discussions and comments.

${ }^{+}$Corresponding author: Robert Fenge, Department of Economics, University of Warwick, Coventry, CV4 7AL, United Kingdom, Phone: ++44-24-765-23481, Fax: ++44-24-765-23032, e-mail: R.Fenge@warwick.ac.uk

+ Matthias Wrede, Department of Economics and Business Administration, RWTH Aachen University, D-52056 Aachen, Germany, Phone: ++49-241-8096154, Fax: ++49-241-8092337, e-mail: mwr@ fiwi.rwthaachen.de 


\title{
EU Regional Policy: \\ Vertical Fiscal Externalities and Matching Grants
}

\begin{abstract}
Although decision processes at the EU level are highly complex and often require unanimity, explicit side payments among member states are unknown. However, logrolling and redistributive policies are substitutes. This paper considers the EU regional policy as a substitute for explicit side payments and asks - from a normative and a positive point of view - why matching grants instead of unconditional grants are used although at first sight regional policy is a national and not a union-wide task. It argues that the EU system of own resources creates positive vertical fiscal externalities. Hence, matching grants are part of an efficient grant system and, in so far as bargaining in EU bodies is efficient, matching grants are the natural outcome.
\end{abstract}

Keywords: European economics, regional policy, intergovernmental grants, side payments, vertical fiscal externalities

JEL-Classification: H54, H77, H87 


\section{Introduction}

Since the mid 1970s regional policy has existed at the EU community level. Today, roughly one third of the EU budget is devoted to structural measures. The regional policy's main objective is to redistribute among regions and countries. Obviously, there is an equity argument for community action in favour of weak economic regions. Furthermore, in the presence of externalities even efficiency might require intergovernmental grants from the community to member states. However, looking at the history of the regional policy, it becomes clear that the funds system in regional policy is mainly an instrument for side payments among member states that are linked to mayor changes in the European Union (see Baldwin et al., 1997; Heinemann, 1999). The first and largest fund in regional policy, the European Regional Development Fund, was created in 1975 when the United Kingdom, Denmark and Ireland became members of the European Union (see Nevin, 1990). When in 1986 Spain and Portugal joined the European Union, the community assumed the competence for its own regional policy with the Single European Act. The ratification was accompanied by a doubling of the structural spending. In 1993 the cohesion fund which benefits Ireland and the southern countries was established in order to enable these countries to meet the Maastricht criteria (see Tondl, 2001). Without the money from the cohesion fund the southern countries were not willing to approve the monetary union and the northern enlargement in 1995. Hence, the regional policy - and even the Common Agriculture Policy - can be considered as a complex system of side payments. Side payments are indispensable to make the decision bodies at the community level work - in particular if unanimity is required - and to achieve Pareto-improvements in a complex system such as the EU (Bird, 1967).

Instead of just giving money to the member states, the structural funds co-finance policy measures by the member states according to common rules laid down by the EU authorities. For instance, the poorer member countries receive 85 per cent of project costs from the cohesion fund. Hence, the funds system makes use of matching grants instead of unconditional grants. However, it is well known from the basic theory of intergovernmental grants that the upper level of government should not distort the decisions at the lower level of government when the aim is simply one of redistribution of resources from the upper to the lower level. 
Only in the presence of externalities is a matching grant superior to an unconditional grant. Indeed, the EU competence in regional policy is usually justified by a hint towards externalities. Under objective one, for instance, EU regional policy focuses on economic and environmental infrastructure. However, there is a lot of anecdotal evidence that cross country external effects are not very large. In the cohesion countries the EU has funded a tremendous improvement of the public road network with reference to Trans European Networks, although the external impact of a new road, for example in the south of Spain, on other member states is clearly not large enough to call for a 85 per cent matching rate. Apart from technological externalities, the public choice approach offers several alternative explanations for the preference for matching grants. Politicians and bureaucrats at the community level have more power with matching grants. Some countries are lacking in efficient and non corrupt institutions to manage regional policy effectively. The EU regional policy is a superior substitute for a missing efficient national administration.

This paper considers the EU regional policy as a substitute for explicit side payments and offers another explanation - from a normative and a positive point of view - of why matching grants instead of unconditional grants are used. It focuses on vertical fiscal externalities created by the EU system of own resources. The budget of the EU is mainly financed from four sources: custom duties levied on products from third countries, levies on the production of sugar, VAT-based own resources and GNP-based own resources. The last two sources account for roughly three-quarters of the EU budget. The VAT-based own resources are shares of their VAT revenues that the member states pay to the European Union. The uniform rate applied to national VAT bases is determined by the community. The GNP-based own resources are contributions of the member states to the European Union where a uniform contribution rate is applied to the GNP. The amount of the GNP resource needed is determined as a residual revenue in order to make up for the difference between total expenditure and the sum of all other revenues. This paper analyses the repercussions of the regional policy on the VAT-based and GNP based own resources.

Regional policy generates a positive vertical fiscal externality in such a EU revenue system. When public infrastructure raises productivity, it also increases the payments of the 
member state to the EU since contributions are (partially) determined by the gross national product. Hence, through the EU budget other member states also benefit from national or local public infrastructure. It is shown that due to these fiscal externalities efficiency requires matching grants. This result confirms the analysis by Dahlby (1996) and Boadway and Keen (1996) who have shown in somewhat different models that in the presence of vertical fiscal externalities vertical transfers are necessary. Furthermore, this paper stresses the strength of the political process in the EU. Arguing that government representatives in EU bodies take the impact of intergovernmental grants on local or national authorities into account, it is shown that EU regional policy will make use of matching grants if regional policy is really a substitute for explicit side payments. In a different setting, Boadway and Keen (1996) have already shown that the upper level of government as a first mover determines the vertical transfer so as to achieve efficiency. In line with their analysis, it is shown here that efficient matching grants will be the outcome of an unbiased bargaining process at the EU community level provided that the EU moves first.

The paper is organised as follows. The model and the results are derived in section two, section three gives a rough estimate of the empirical importance of the effects, and section four concludes.

\section{The model}

The model is a two-period model which analyses a union consisting of two countries. One country is a receiver of resources, the other country, indicated by an asterisk, is a net payer. The two countries play a simple three-stage game. At the first stage, they decide cooperatively on the size of unconditional grants and on a matching grant rate, i.e. a rate by which the union co-finances public infrastructure in the receiver country. At the second stage, the receiver country decides how much national resources are devoted to public infrastructure given the matching grant rate. At the third stage, savings, investment, production and consumption take place in both countries. 
The analysis starts with the third stage. For simplicity, gross income per capita in the net-payer country in both periods is not endogenously determined: $y_{1} *$ and $y_{2} *{ }^{1}$. The population is homogeneous in each country. The population size is constant in both countries and denoted by $L$ and $L^{*}$, respectively. Since income and population in the net-payer country are fixed, the following analysis of the third stage focuses on the receiver country. The factors of production in that country are labour, capital and public infrastructure. Labour is internationally immobile and each individual supplies inelastically exactly one unit of labour. Capital, denoted by $K$, is internationally mobile. Compared with the rest of the world the union is small, so capital earns the constant world interest rate $r$. Public infrastructure is indicated by $G$. Production takes place according to a linearly homogeneous production function with positive but decreasing marginal products: $F(L, K, G)=L f(k, g)$, where the per-capita variables are denoted by lower-case variables. Public infrastructure and capital are complementary: $F_{K G}=$ $f_{k g} / L>0 .{ }^{2}$ Public infrastructure is rival but free of charge. The depreciation rates of capital and public infrastructure are zero. The wage rate in period $i$ is denoted by $w_{i}$. Then, the aggregate profit in period $i, i=1,2$, is

$\Pi_{i}=F\left(L, K_{i}, G_{i}\right)-w_{i} L_{i}-r K_{i}$.

Profit maximisation leads to $F_{K}\left(L, K_{i}, G_{i}\right)=r$ and $F_{L}\left(L, K_{i}, G_{i}\right)=w_{i}$. Hence, the aggregate profit $\Pi_{i}=F_{G}\left(L, K_{i}, G_{i}\right) G_{i}$ is strictly positive. It is assumed that the number of (identical) firms in the country is exogenous. Furthermore, the firms are domestically owned and property rights are equally distributed among the population. Capital in period one is, for the sake of concreteness, also domestically owned. Using the first-order conditions with respect to capital and labour and taking into account that the wage rate changes to adapt labour demand to labour supply, the impact of an increase in the quantity of public infrastructure on capital can be derived as $d K_{i} / d G_{i}=d k_{i} / d g_{i}=-f_{k g} / f_{k k}>0$.

\footnotetext{
1 To endogenise income of the net-payer country is a simple exercise, but does not provide additional insight.

2 Partial derivatives are indicated by subscripts.
} 
A household's income consists of labour income, a profit share and capital income. In each period income is used for consumption, savings and, by assumption, VAT taxation. As a result, within the two-period framework the budget constraints are

$$
\begin{aligned}
& (1+\delta) c_{1}=\Pi_{1} / L+w_{1}-s+(1+r) k_{1}, \\
& (1+\delta) c_{2}=\Pi_{2} / L+w_{2}+(1+r) s,
\end{aligned}
$$

where $s$ denotes gross savings in period $1, c_{i}$ is consumption in period i and $\delta$ is the uniform VAT tax rate in both periods. The household derives utility from private consumption and a union public good $P_{i}$ in each period i, with $P_{i}>0: u\left(c_{1}, c_{2}, P_{1}, P_{2}\right)$, where u is a strictly quasiconcave utility function. For the ease of exposition we assume the utility function to exhibit additive separability. Hence, cross derivatives of the utility function are zero, especially $u_{c_{1} c_{2}}=u_{c_{2} c_{1}}=0$. By the choice of savings $s$ the household maximises $u\left(c_{1}, c_{2}, P_{1}, P_{2}\right)$ subject to the two budget constraints, taking the wage rates, the interest rate, profits and union public good quantities as given. At the household optimum the marginal rate of substitution $u_{c_{1}} / u_{c_{2}}$ equals the price of period-one consumption $1+r$. The indirect utility function can be written as $v\left(y, r, P_{1}, P_{2}\right)$, where $y$ is the present value of income net of taxes:

$$
y=\Pi_{1} / L+w_{1}+(1+r) k_{1}-\delta c_{1}+\left(\Pi_{2} / L+w_{2}-\delta c_{2}\right) /(1+r) .
$$

The government of the receiver country invests in public infrastructure $g_{2}-g_{1}$ and contributes to the union budget in two ways. The union receives a share of the VAT tax revenues of the member states and it obtains contributions from the member states. We reproduce the EU procedure of balancing the budget by assuming the following in the model. The VAT tax share is determined exogenously at a rate $t / \delta$, where $t$ is fixed so that $0<t / \delta<1$. The contributions are defined in terms of gross domestic product. ${ }^{3}$ The contribution rates are determined endogenously in order to fill up the gap in the union's budget between expenditure and VAT share. That is, the receiver country pays as VAT tax share $t c_{i}$ and contributes $\tau_{\mathrm{i}} \mathrm{Lf}\left(\mathrm{k}_{\mathrm{i}}, \mathrm{g}_{\mathrm{i}}\right)$ in period $\mathrm{i}$, where $\tau_{i}$ denotes the contribution rate in period i. From the union's

\footnotetext{
Since the international economic transactions are modeled only rudimentary, defining contributions in terms of gross domestic product fits best. However, the analysis would not be changed substantially if contributions were defined in terms of gross national product.
} 
budget the country receives per capita an unconditional grant $z$ in period 1 and a conditional grant $\alpha\left(g_{2}-g_{1}\right)$. Furthermore, the government levies VAT taxes within the country and runs, possibly, a debt. However, at period 2, debt is redeemed. Therefore, in per-capita terms the government budget constraints in the receiver country are

$$
\begin{aligned}
& g_{1}+\delta c_{1}+z+\alpha\left(g_{2}-g_{1}\right)+d=\tau_{1} f\left(k_{1}, g_{1}\right)+t c_{1}+g_{2}, \\
& g_{2}+\delta c_{2}=\tau_{2} f\left(k_{2}, g_{2}\right)+t c_{2}+(1+r) d,
\end{aligned}
$$

where $d$ denotes public debt per capita.

The country as a whole potentially borrows from the rest of the world, but foreign debt is redeemed in period two. Indicating per-capita foreign debt by $b$, the capital market equilibrium condition in per-capita terms is $k_{2}+d=s+b$.

Hence, from the household-budget constraints, the government budget constraints and the capital-market equilibrium, the resource constraints in the receiver country in per-capita terms can be derived as

$$
\begin{aligned}
& (1+t) c_{1}=\left(1-\tau_{1}\right) f\left(k_{1}, g_{1}\right)-(1-\alpha)\left(g_{2}-g_{1}\right)+z+b-\left(k_{2}-k_{1}\right), \\
& (1+t) c_{2}=\left(1-\tau_{2}\right) f\left(k_{2}, g_{2}\right)+k_{2}+g_{2}-(1+r) b .
\end{aligned}
$$

The union finances with the VAT tax shares and the contributions of the member states unconditional and conditional grants to the receiver country and public consumption goods, which are non-rival at the union level. The union is excluded from getting into debt by constitutional constraints. The union's budget constraints are given by:

$$
\begin{aligned}
& \tau_{1}\left(L f\left(k_{1}, g_{1}\right)+L * y_{1} *\right)+t\left(L c_{1}+L * c_{1} *\right)=P_{1}+L\left(\alpha\left(g_{2}-g_{1}\right)+z\right) \\
& \tau_{2}\left(L f\left(k_{2}, g_{2}\right)+L * y_{2} *\right)+t\left(L c_{2}+L * c_{2} *\right)=P_{2}
\end{aligned}
$$

The public good quantities and the VAT shares are exogenous, but by adjustments of the contribution rates, which are the same for both countries, the union's budget is balanced in every period. Taking into account the resource constraints (1) we yield: 
$\tau_{1}=\frac{P_{1}+L\left(\alpha\left(g_{2}-g_{1}\right)+z\right)-\theta\left(L R_{1}+L * R_{1} *\right)}{(1-\theta)\left(L f\left(k_{1}, g_{1}\right)+L * y_{1} *\right)}$ and $\tau_{2}=\frac{P_{2}-\theta\left(L R_{2}+L * R_{2} *\right)}{(1-\theta)\left(L f\left(k_{2}, g_{2}\right)+L * y_{2} *\right)}$,

where $\theta \equiv t /(1+t)$ is the gross VAT tax rate and $R_{1}$ and $R_{2}$ are defined as:

$$
\begin{aligned}
& R_{1}=f\left(k_{1}, g_{1}\right)-(1-\alpha)\left(g_{2}-g_{1}\right)+z+b-\left(k_{2}-k_{1}\right) \quad \text { and } \\
& R_{2}=f\left(k_{2}, g_{2}\right)+k_{2}+g_{2}-(1+r) b
\end{aligned}
$$

The next step is to analyse the second stage, where the receiver country decides on public infrastructure. It is assumed that the government maximises the welfare of the representative consumer $v\left(y, r, P_{1}, P_{2}\right)$. Taking the budget constraints of households and the government, the capital market equilibrium condition and the budget constraints of the union into account, the government simply maximises the present value of the consumer's net income, i.e., it solves

$$
\begin{aligned}
& \underset{g_{2}}{\operatorname{Max}} y, \text { where } \\
& y=\left(1-\tau_{1}\right) f\left(k_{1}, g_{1}\right)+\frac{1}{1+r}\left[\left(1-\tau_{2}\right) f\left(k_{2}, g_{2}\right)\right] \\
& \quad-\theta\left[\left(1-\tau_{1}\right) f\left(k_{1}, g_{1}\right)-\left(k_{2}-k_{1}\right)+z-(1-\alpha)\left(g_{2}-g_{1}\right)+\frac{1}{1+r}\left[\left(1-\tau_{2}\right) f\left(k_{2}, g_{2}\right)+k_{2}+g_{2}\right]\right] \\
& \quad+k_{1}+g_{1}+z+\alpha\left(g_{2}-g_{1}\right)-\frac{r}{1+r}\left(k_{2}+g_{2}\right)
\end{aligned}
$$

and $\tau_{1}$ and $\tau_{2}$ are defined as given above. Inserting all the budget constraints, the present value of consumer's net income is, in present value per capita terms, the sum of domestic output net of contributions to the union minus the VAT tax shares to the union plus the endowment at the beginning of private capital and public infrastructure plus unconditional and conditional grants minus the loss due to the postponement of consumption of private capital and public infrastructure. 
The optimisation problem is so simple because the national government just provides public infrastructure, the only national tax is VAT, the interest rate is exogenously determined by the world capital market and the union public good quantities are also exogenous. Therefore, the present value of net income is the single argument of the indirect utility function which the government can change. Furthermore, indirect utility is strictly monotonically increasing in net income $y$. Hence, $\operatorname{argmax} \quad \mathrm{v}\left(\mathrm{y}\left(\mathrm{g}_{2}\right), \mathrm{r}, \mathrm{P}_{1}, \mathrm{P}_{2}\right)=\operatorname{argmax} \mathrm{y}\left(\mathrm{g}_{2}\right)$.

An interior solution of the government's optimisation problem is characterised by ${ }^{4}$

$$
\begin{aligned}
\frac{d y}{d g_{2}} & =\frac{1-\theta}{1+r}\left[\left(1-\tau_{2}\right) f_{g}^{2}-r+\alpha(1+r)-\tau_{2} r \frac{d k_{2}}{d g_{2}}-(1+r) f\left(k_{1}, g_{1}\right) \frac{d \tau_{1}}{d g_{2}}-f\left(k_{2}, g_{2}\right) \frac{d \tau_{2}}{d g_{2}}\right] \\
& =0
\end{aligned}
$$

with

$$
\frac{d \tau_{1}}{d g_{2}}=\frac{L}{(1-\theta)\left(L f\left(k_{1}, g_{1}\right)+L * y_{1} *\right)}\left[\alpha+\theta\left(\frac{d k_{2}}{d g_{2}}-\frac{d b}{d g_{2}}+(1-\alpha)\right)\right]
$$

and

$$
\begin{aligned}
\frac{d \tau_{2}}{d g_{2}}= & -\frac{L}{(1-\theta)\left(L f\left(k_{2}, g_{2}\right)+L^{*} y_{2} *\right)} \\
& \cdot\left[\theta\left[\left(f_{k}^{2} \frac{d k_{2}}{d g_{2}}+f_{g}^{2}\right)+\frac{d k_{2}}{d g_{2}}+1-(1+r) \frac{d b}{d g_{2}}\right]+\tau_{2}(1-\theta)\left(f_{k}^{2} \frac{d k_{2}}{d g_{2}}+f_{g}^{2}\right)\right]
\end{aligned}
$$

In general, the government does not invest in public infrastructure up to the point where the marginal product of public infrastructure $F_{G}=f_{g}$ is equal to the interest rate. Therefore, the marginal products of private and public capital may not be equalised. From an international point of view, the allocation of resources is not always first-best efficient. Furthermore, if the government neglected the impact of public infrastructure on the contribution

\footnotetext{
$4 \quad \mathrm{f}^{\mathrm{i}}$ is an abbreviation for $\mathrm{f}\left(\mathrm{k}_{\mathrm{i}}, \mathrm{g}_{\mathrm{i}}\right)$.
} 
rates via grants and the gross domestic product in period two, it would equalise the marginal product of public infrastructure net of contributions $\left(1-\tau_{2}\right) f_{g}^{2}$ with the interest rate minus the value of the conditional grant per unit in the second period $r-\alpha(1+r)$ minus the impact on contributions via the change in private capital $\tau_{2} r d k_{2} / d g_{2}$. Compared with the internationally first-best efficient level of public infrastructure, overprovision as well as underprovision is possible. If the receiver country did not contribute to the union's budget, i.e., if $\tau_{2} \equiv 0\left(\equiv \tau_{1}\right)$, the grant would clearly cause overprovision.

If, however, the government takes the change in the contribution rates into account, additional ambiguity comes into play. In the first period additional investment in public infrastructure increases the union's expenditure and, if $d k_{2} / d g_{2}>d b / d g_{2}$, decreases the VAT tax base. Therefore, the contribution rate in the first period tends to rise. But in the second period, under the same condition, investment in public infrastructure decreases the contribution rate due to the increase in gross domestic product and an increase of the VAT tax base.

Proposition 1 (Underprovision of public infrastructure). Compared with the first-best rule the receiver country undersupplies public infrastructure if the country does not receive a conditional grant $(\alpha=0)$.

Proof. See Appendix A.

The intuition for this result is that via the contribution to the union's budget in the second period the receiver country let the union have part of the benefits of investment in public infrastructure. This positive vertical externality implies an inefficient underinvestment in infrastructure.

Now, the first stage of the game has to be analysed. At this stage, receiver country and net-payer country take the behaviour of the receiver country's government into account. A situation is considered where the members of the union have to decide unanimously on some particular project (for example, a change in the rules of the union). By assumption, only the net-payer country benefits from a positive vote, while the receiver country is harmed. The government of the receiver country is willing to consent to the project if the population 
achieves a minimum utility level $\bar{v}$. It is the affair of the net-payer country's government to determine the composition of grants. However, given the approval of the receiver country, the net-payer country's government wants to minimise its payments to the union's budget in present value terms. Hence, the government of this country solves

$$
\underset{\alpha, z}{\operatorname{Min}} L *\left[\theta\left(R_{1} *+\frac{R_{2} *}{1+r}\right)+(1-\theta)\left(\tau_{1} y_{1} *+\frac{\tau_{2} y_{2} *}{1+r}\right)\right] \text { s.t. } v\left(y(\alpha, z), r, P_{1}, P_{2}\right) \geq \bar{v} \text {. }
$$

Here, it is assumed that the government of the net-payer country also act's in the national interest. In the following analysis, the dual problem

$$
\underset{\alpha, z}{\operatorname{Max}} v\left(y(\alpha, z), r, P_{1}, P_{2}\right) \text { s.t. } L *\left[\theta\left(R_{1} *+\frac{R_{2} *}{1+r}\right)+(1-\theta)\left(\tau_{1} y_{1} *+\frac{\tau_{2} y_{2} *}{1+r}\right)\right]=\bar{T}
$$

is considered, where $\bar{T}$ is an adequately adjusted payment in present value terms. The entire problem of the three-stage game has a simple solution, which is stated by the following proposition.

Proposition 2 (Efficiency). The government of the net-payer country determines unconditional grants and the matching grant rate at the first-stage of the three-stage game such that the government of the receiver country will invest up to the point at which the marginal product of public infrastructure is equal to the world interest rate.

Proof. See Appendix B.

As a result of the multi-stage decision process, the allocation of resources is first-best efficient from an international efficiency point of view. ${ }^{5}$ The reasons for this result are twofold. First, the government of the net-payer country actually maximises international welfare instead of just national welfare at the first stage of the game since it has to concede the receiver country a particular utility level. The bargaining situation at this stage of the game ensures efficiency.

5 If the solution were a corner solution, the results would slightly change. Some efficiency losses are possible. 
Second, the actors are foresighted as they take the adjustment at the following stages of the game into account.

Proposition 3 (Optimum matching grant). The optimum matching grant rate is

$$
\alpha=\tau_{2} \frac{r}{1+r}\left(1+\frac{d k_{2}}{d g_{2}}\right)\left(\frac{L f^{1}+(1-\theta) L^{*} y_{1} *}{L f^{2}+(1-\theta) L^{*} y_{2} *}\right) \frac{y_{2} *}{y_{1} *}>0 .
$$

Proof. Inserting $\mathrm{f}_{\mathrm{g}}^{2}=\mathrm{r}$ in (A3) in the appendix and solving for $\alpha$ yields the proposition immediately.

From an international efficiency point of view, the union's policy should rely (partially) on conditional grants. The decision of the receiver country should be distorted through conditional grants, since the benefits of public infrastructure go in part to the net-payer country via the gross-domestic-product based contributions to the union. Hence, the conditional grant serves as a fiscal "Pigouvian" subsidy that internalises the positive vertical fiscal externality of the contributions to the union budget.

The formula of the optimum grant rate reveals that the vertical fiscal externality and, therefore, the optimum matching grant rate is higher, the higher the contribution rate $\tau_{2}$ or the marginal impact of infrastructure on capital $d k_{2} / d g_{2}$ is. Furthermore, the effect rises if the growth rate of per-capita GDP or the population of the net payer country increases or of the net receiver country decreases. Now the policy of the EU is to lower the VAT share paid by member states to the EU. If $\theta$ decreases the impact on the externality and the matching rate is ambiguous. According to the partial derivation of $\alpha$ from (6) the fiscal externality diminishes if the GDP growth rate of the net payer country is higher than that of the net receiver country and vice versa: 
$\frac{\partial \alpha}{\partial \theta} \leq(\geq) 0 \Leftrightarrow \frac{y_{2} *}{y_{1} *} \leq(\geq) \frac{f^{2}}{f^{1}}$.

In fact, as we will see in the next section the net receiver countries in the EU15 grow faster than the net payer countries in the last years. Hence, the EU policy of extending the GNPrelated contributions and reducing the VAT share of the member states implies an increasing vertical fiscal externality which in turn calls for higher matching rates in regional policy.

\section{The magnitude of the vertical fiscal externality}

How large is this positive vertical fiscal externality of public infrastructure? We can measure the external effect by calculating the value of the expression on the right hand side of (6).

We compute the effect for different values of contribution rates and VAT share rates in the years 2001 and 2002. This is because in the Agenda 2000 negotiations the member states of the EU agreed on major changes with regard to the revenue side of the EU budget as a result of which the VAT tax share was determined to fall and the contribution rate to rise. In consequence, the uniform VAT rate $t^{6}$ applied to the VAT base of member states has been reduced from 0.75 per cent in 2001 to 0.53 per cent in 2002 . The contribution rate on GNP has increased endogenously from 0.4 per cent in 2001 to 0.5 per cent in $2002^{7}$.

\footnotetext{
${ }^{6}$ The uniform rate $t$ applied to the VAT bases of the member states is calculated by subtracting a so-called "frozen" rate from the negotiated maximum rate (2001: 1 per cent; 2002: 0.75 per cent). The frozen rate is a correction term for concessions to the United Kingdom and reduced contributions of Germany, the Netherlands, Austria and Sweden to this concession. The contribution rate $\tau_{2}$ on the GNP of the member states results endogenously as the share of the GNP resource needed to make up for the difference between total expenditure and the sum of all other revenue. For details of the calculation see the Council Decision of 29 September 2000 on the system of the European Communities' own esources (2000/597/EC, Euratom)

${ }^{7}$ See EU Financial report 2001, p.26 and EU Financial report 2002, p.19.
} 
In a first step of the calculation the net payer and the net receiver country are assumed to have the same size of population and GDP per capita: $L=L^{*}, f^{i}=y_{i}^{*}, i=1,2$. Then the expression in (6) of the vertical fiscal externality (VFE) reduces to:

$V F E=\tau_{2} \frac{r}{1+r}\left(1+\frac{d k_{2}}{d g_{2}}\right)$.

This expression can be easily interpreted. Infrastructure affects GDP and, hence, contribution payments to the EU in two ways: first directly and second via its complementarity with private capital. Thus the vertical fiscal externality increases with the contribution rate, the direct effect $\left(f_{g}=r\right)$, and the indirect effect $f_{k}^{2} \frac{d k_{2}}{d g_{2}}$.

For measuring the real effect of infrastructure on GDP we have to take into account that infrastructure has a long-term effect of several decades and not only for two periods (years) as in our model. Although the contribution rate $\tau$ can be expected to increase over the next years according to the announced EU policy which would imply an even higher vertical fiscal externality, we assume that the contribution rate, the direct and the indirect effect of infrastructure remain the same for the next decades. For $n$ years the vertical fiscal externality can be measured by the following expression: $V F E=\tau_{2}\left(1+\frac{d k_{2}}{d g_{2}}\right) \cdot\left(1-\frac{1}{(1+r)^{n-1}}\right)$.

We consider the infrastructure effect over a time horizon of $n=50$ years and we project a real interest rate $r$ of 4 per cent. We estimate the marginal impact of an increase in public infrastructure on capital on basis of a Cobb-Douglas production function: $F\left(K_{i}, L, G_{i}\right)=K_{i}^{\beta} \cdot G_{i}^{\gamma} \cdot L^{1-\beta-\gamma}$. Hence, $d k_{2} / d g_{2}=-\gamma k_{2} /(\beta-1) g_{2}$. 
At a first guess we would expect that the impact of public infrastructure like roads and highways (about 50 per cent of the public infrastructure in Germany), bridges and railways, water and sewer systems, dikes and ports, airports etc., is not negligible. However, there is a large empirical literature measuring the productivity of public infrastructure which is far from unanimity ${ }^{8}$. Aschauer (1989) set off the debate by estimating with US data the output elasticity of infrastructure on the national level at about 0.39. Other studies at that time estimated a similar high productivity of public infrastructure (Munnell, 1990a with 0.34; Holz-Eakin, 1988 with 0.39). These results were challenged by some authors who questioned the approach of Aschauer and others and found the elasticity too high to be plausible (e.g. Tatom, 1991). Especially public capital on the regional level was found to have a significantly lower output elasticity (Duffy-Deno and Eberts, 1989: 0.08; Garcia-Mila and McGuire, 1992: 0.05; Seitz, 1995: 0.08-0.19). However, recent studies have confirmed the rather high effect of infrastructure on GDP. With Canadian data Wylie (1996) estimated an output elasticity of infrastructure capital as high as 0.52 . Fernald (1999) measured the elasticity of roads, the largest component of US infrastructure, at about 0.35 . On basis of German data from the manufacturing sector Stephan (2001) estimated output elasticities of infrastructure in the range between 0.42 to 0.65 . As a consequence of this debate we assume the following output elasticities: $\beta=0.25, \gamma=0.40$.

The ratio of private to public capital, $k_{2} / g_{2}$, was in Germany between 1970 and 1995 in the range of 1.17 to 0.81 (Stephan, 2001). Finding similar ratios in the US (Morrison and Schwartz, 1996) we assume a ratio of unity. Now we can calculate that in this benchmark case the vertical fiscal externality amounts to 0.527 per cent in 2001 and 0.672 per cent in

\footnotetext{
${ }^{8}$ A survey until 1992 is provided by Munnell (1992).
} 
2002. Expecting that the GNP-contribution rate will rise further at the same pace the external effect can be assumed to reach a value around 1 per cent.

Now dropping the assumption of equal population and GDP size of the net payer and the net receiver countries we compare the economic area of all EU15 net payer countries in the relevant period with the economic area of all net receiver countries. The net payer countries $^{9}$ combined had a GNP per capita of Euro 24192 in 2000, Euro 24933 in 2001, and Euro 25693 in 2002 . The net receiver countries ${ }^{10}$ comprised a GNP per capita of Euro 14880 in 2000, Euro 15964 in 2001, and Euro 16812 in $2002^{11}$. Hence, the growth rate of the economic area of the net receiver countries was in both years higher than the growth rate of the net payer countries. Our result do not change significantly. In 2001 the vertical fiscal externality was 0.524 per cent and in 2002 it was 0.668 per cent.

\section{Conclusion}

This paper considers the EU regional policy as a substitute for explicit side payments and asked - from a normative and a positive point of view - why matching grants instead of unconditional grants are used. The message of the paper is twofold.

First, theoretically we identify a positive vertical fiscal externality of public infrastructure which is generated by the EU revenue system of own resources. If a region invests in infrastructure the repercussions of its higher GNP-related (GDP-related) contributions to the EU facilitating the duty of EU-payments from other member states are not taken into account. Neglecting this welfare effect on other regions a jurisdiction provides an inefficiently low en-

\footnotetext{
${ }^{9}$ Austria, Belgium, Denmark, Germany, Finland, France, Italy, Luxembourg, the Netherlands, Sweden, and the United Kingdom.

${ }^{10}$ Greece, Spain, Ireland, and Portugal.

${ }^{11}$ Source: Eurostat, Statistics in focus, Economy and finance, Theme 2, 1/2002, 53/2002, 56/2003. For the population data see Eurostat, Statistics in focus, Population and social conditions, Theme 3, 16/2000, 19/2001, 25/2002.
} 
dowment of infrastructure. Therefore, we can offer a justification why the EU regional policy employs matching grants in order to support the regional investment in infrastructure: matching grants are part of an efficient grant system. Based on the assumption that governments at the EU community level move before national or local governments execute regional policy, the paper shows that matching grants are indeed a part of the EU system if grants under the label of regional policy are a substitute for explicit side payments governments and in so far as bargaining in EU bodies is efficient. Hence, a pure system of unconditional grants in the EU is neither efficient nor the outcome of political processes.

Second, according to a rough estimate the vertical fiscal externality seems to be of a quite small size. Thus, matching grant rates in the magnitude of 85 per cent as are granted by the cohesion funds would be far beyond the efficient matching grant rate if only the vertical fiscal externality were to be internalised. Other reasons for the steering mechanism of matching grants like technological externalities or the interests of EU bureaucrats and politicians at the community level have to be added in order to totally explain the high matching grants. 


\section{Appendix}

\section{A: Proof of Proposition 1}

Proof. Inserting $\frac{d \tau_{1}}{d g_{2}}$ and $\frac{d \tau_{2}}{d g_{2}}$ from equations (3) and (4) in the first-order condition (2) yields

$$
\begin{aligned}
\frac{d y}{d g_{2}} & =\frac{1}{1+r}\left\{\left(1+f_{g}^{2}\right)\left(1-\theta \frac{L^{*} y_{2} *}{L f\left(k_{2}, g_{2}\right)+L^{*} y_{2} *}\right)-(1+r)\left(1-\theta \frac{L^{*} y_{1} *}{L f\left(k_{1}, g_{1}\right)+L * y_{1} *}\right)\right. \\
& -\tau_{2}\left(f_{k}^{2} \frac{d k_{2}}{d g_{2}}+f_{g}^{2}\right)(1-\theta) \frac{L^{*} y_{2} *}{L f\left(k_{2}, g_{2}\right)+L * y_{2} *}+\alpha(1+r)(1-\theta) \frac{L^{*} y_{1} *}{L f\left(k_{1}, g_{1}\right)+L^{*} y_{1} *} \\
& \left.+\theta(1+r)\left(\frac{d b}{d g_{2}}-\frac{d k_{2}}{d g_{2}}\right)\left(\frac{L^{*} y_{2} *}{L f\left(k_{2}, g_{2}\right)+L^{*} y_{2} *}-\frac{L^{*} y_{1} *}{L f\left(k_{1}, g_{1}\right)+L^{*} y_{1} *}\right)\right\} \\
& =0
\end{aligned}
$$

Now we determine the impact of public infrastructure on foreign debt $d b / d g_{2}$. Applying the implicit function theorem to the consumer's first-order condition, $\mathrm{u}_{\mathrm{c}_{1}}-(1+\mathrm{r}) \mathrm{u}_{\mathrm{c}_{2}}=0$, yields that the response of foreign debt to changes in infrastructure is positive:

$$
\begin{aligned}
& \frac{d b}{d g_{2}}=\frac{1}{u_{c_{1} c_{1}}\left(\frac{(1-\theta) L^{*} y_{1} *+L f\left(k_{1}, g_{1}\right)}{L f\left(k_{1}, g_{1}\right)+L^{*} y_{1} *}\right)+u_{c_{2} c_{2}}(1+r)^{2}\left(\frac{(1-\theta) L^{*} y_{2} *+L f\left(k_{2}, g_{2}\right)}{L f\left(k_{2}, g_{2}\right)+L^{*} y_{2} *}\right)} \\
& \left\{u_{c_{1} c_{1}}\left(\frac{L f\left(k_{1}, g_{1}\right)\left(1+\frac{d k_{2}}{d g_{2}}\right)+(1-\theta) L^{*} y_{1} *\left(1-\alpha+\frac{d k_{2}}{d g_{2}}\right)}{L f\left(k_{1}, g_{1}\right)+L^{*} y_{1} *}\right)\right. \\
& \left.+u_{c_{2} c_{2}}(1+r)\left(\frac{L f\left(k_{2}, g_{2}\right)\left(f_{k}^{2} \frac{d k_{2}}{d g_{2}}+f_{g}^{2}+\frac{d k_{2}}{d g_{2}}+1\right)+(1-\theta) L * y_{2} *\left[\left(1-\tau_{2}\right)\left(f_{k}^{2} \frac{d k_{2}}{d g_{2}}+f_{g}^{2}\right)+\frac{d k_{2}}{d g_{2}}+1\right]}{L f\left(k_{2}, g_{2}\right)+L^{*} y_{2} *}\right)\right\}
\end{aligned}
$$


If we insert the foreign debt response (A2) in the first-order condition (A1) and solve for $f_{g}^{2}$ we yield

$$
\begin{aligned}
f_{g}^{2}= & r \frac{L f\left(k_{2}, g_{2}\right)+(1-\theta) L * y_{2} *\left(1+\tau_{2} \frac{d k_{2}}{d g_{2}}\right)}{L f\left(k_{2}, g_{2}\right)+(1-\theta) L * y_{2} *\left(1-\tau_{2}\right)} \\
& -\alpha(1+r)(1-\theta) \frac{L * y_{1} *}{L f\left(k_{1}, g_{1}\right)+(1-\theta) L^{*} y_{1} *} \cdot \frac{L f\left(k_{2}, g_{2}\right)+(1-\theta) L * y_{2} *}{L f\left(k_{2}, g_{2}\right)+(1-\theta) L^{*} y_{2} *\left(1-\tau_{2}\right)}
\end{aligned}
$$

For $\alpha=0$, (A3) implies $f_{g}^{2}>r$ which yields the proposition.

\section{B: Proof of proposition 2:}

Proof. The first-order condition of the net-payer country for an interior solution at the first stage is

$$
\frac{d v}{d \alpha}=\frac{\partial v}{\partial y}\left(\frac{\partial y}{\partial \alpha}+\frac{\partial y}{\partial z} \frac{d z}{d \alpha}\right)=0 .
$$

The revenue constraint in (5) determines the unconditional grant $\mathrm{z}$ as a function of the matching grant rate $\alpha$ :

$$
\frac{d z}{d \alpha}=-\frac{\frac{\partial T}{\partial \alpha}+\frac{\partial T}{\partial g_{2}} \frac{\partial g_{2}}{\partial \alpha}}{\frac{\partial T}{\partial z}+\frac{\partial T}{\partial g_{2}} \frac{\partial g_{2}}{\partial z}}
$$

where the left-hand side of the revenue constraint is defined as $T\left(g_{2}(\alpha, z), \alpha, z\right)$ and $\partial g_{2} / \partial \alpha$ and $\partial g_{2} / \partial z$ result from the first-order condition of the second stage: $d y / d g_{2}=0$. Since $\partial y / \partial \alpha=\left(g_{2}-g_{1}\right)(\partial y / \partial z)$ and $\partial T / \partial \alpha=\left(g_{2}-g_{1}\right) \partial T / \partial z$ and using (A5), condition (A4) can be written as

$$
\frac{d v}{d \alpha}=\frac{\partial v}{\partial y} \frac{\partial y}{\partial z}\left[\frac{\left(\left(g_{2}-g_{1}\right) \frac{\partial g_{2}}{\partial z}-\frac{\partial g_{2}}{\partial \alpha}\right) \frac{\partial T}{\partial g_{2}}}{\frac{\partial T}{\partial z}+\frac{\partial T}{\partial g_{2}} \frac{\partial g_{2}}{\partial z}}\right]=0 .
$$

The partial derivative of $T\left(g_{2}(\alpha, z), \alpha, z\right)$ with respect to $g_{2}$, using $d y / d g_{2}=0$, is given by: 
$\frac{\partial T}{\partial g_{2}}=-\frac{\left(f_{g}^{2}-r\right) L}{1+r}$

Inserting (A7) together with $\partial T / \partial z=L \partial y / \partial z$ in (A6) yields:

$\frac{d v}{d \alpha}=\frac{\partial v}{\partial y} \frac{\partial y}{\partial z}\left(f_{g}^{2}-r\right)\left[\frac{\frac{\partial g_{2}}{\partial \alpha}-\left(g_{2}-g_{1}\right) \frac{\partial g_{2}}{\partial z}}{(1+r) \frac{\partial y}{\partial z}-\left(f_{g}^{2}-r\right) \frac{\partial g_{2}}{\partial z}}\right]=0$

Since $\partial v / \partial y>0$ and

$\frac{\partial y}{\partial z}=\frac{(1-\theta) y_{1} * L *\left(f_{2} L+(1-\theta) y_{2} * L *\right)\left(u_{c_{1} c_{1}}+(1+r)^{2} u_{c_{2} c_{2}}\right)}{\left(f_{2} L+y_{2} * L *\right)\left(f_{1} L+(1-\theta) y_{1} * L *\right) u_{c_{1} c_{1}}+(1+r)^{2}\left(f_{1} L+y_{1} * L *\left(f_{2} L+(1-\theta) y_{2} * L *\right) u_{c_{2} c_{2}}\right.}>0$

it remains to be shown that the numerator in the squared brackets of condition (A8) is not zero. In

that case (A8) reveals that the net payer country chooses the grants efficiently $\left(f_{g}^{2}=r\right)$.

Using $d y / d g_{2}=0$ the numerator can be written as:

$$
\begin{aligned}
& \frac{\partial g_{2}}{\partial \alpha}-\left(g_{2}-g_{1}\right) \frac{\partial g_{2}}{\partial z}= \\
& \frac{1}{d^{2} y / d g_{2}^{2}} \frac{\theta L L *\left(f_{2} y_{1} *-y_{2} * f_{1}\right)\left[\frac{\partial^{2} b}{\partial g_{2} \partial \alpha}-\left(g_{2}-g_{1}\right) \frac{\partial^{2} b}{\partial g_{2} \partial z}\right]-(1-\theta)\left(f_{2} L+y_{2} * L * y_{1} * L *\right.}{\left(f_{2} L+y_{2} * L *\right)\left(f_{1} L+y_{1} * L *\right)}
\end{aligned}
$$

Since from (A2) follows

$$
\frac{\partial^{2} b}{\partial g_{2} \partial \alpha}-\left(g_{2}-g_{1}\right) \frac{\partial^{2} b}{\partial g_{2} \partial z}=-\frac{\left[\frac{(1-\theta) L * y_{1} *}{L f_{1}+L * y_{1} *}\right] u_{c_{1} c_{1}}}{\left(\frac{L f_{1}+(1-\theta) L * y_{1} *}{L f_{1}+L * y_{1} *} u_{c_{1} c_{1}}+\frac{(1+r)^{2}\left(L_{2}+(1-\theta) L * y_{2} *\right)}{L f_{2}+L * y_{2} *} u_{c_{2} c_{2}}\right)}<0
$$

the numerator can be shown to be positive: 


$$
\begin{aligned}
& \frac{\partial g_{2}}{\partial \alpha}-\left(g_{2}-g_{1}\right) \frac{\partial g_{2}}{\partial z}=-\frac{1}{d^{2} y / d g_{2}^{2}} \\
& \left.\left[\frac{(1-\theta)\left(f_{2} L+y_{2} * L *(1-\theta)\right) y_{1} * L *\left(u_{c_{1} c_{1}}+(1+r)^{2} u_{c_{2} c_{2}}\right)}{\left(f_{2} L+y_{2} * L *\right)\left(f_{1} L+y_{1} * L *\right)\left(\frac{L f_{1}+(1-\theta) L^{*} y_{1} *}{L f_{1}+L * y_{1} *} u_{c_{1} c_{1}}+\frac{(1+r)^{2}\left(L f_{2}+(1-\theta) L^{*} y_{2} *\right)}{L f_{2}+L^{*} y_{2} *} u_{c_{2} c_{2}}\right)}\right)\right] \\
& >0
\end{aligned}
$$

This completes the proof. 


\section{References}

Aschauer, D.A. (1989), "Is Public Expenditure Productive?", Journal of Monetary Economics $23,177-200$.

Baldwin, R.E., J.F. Francois and R. Portes (1997), “The Costs and Benefits of Eastern Enlargement: The Impact on the EU and Central Europe", Economic Policy 12, 125 176.

Bird, R.M. (1967), "Regional Policies in a Common Market", in: C. Shoup (ed.), Fiscal Harmonization in Common Markets, Volume 1: Theory, New York and London.

Boadway, R. and M. Keen (1996), "Efficiency and the Optimal Direction of Federal-State Transfers", International Tax and Public Finance 3, 137 - 155.

Dahlby, B. (1996), 'Distortionary Taxation and the Design of Intergovernmental Grants", International Tax and Public Finance 3, 397 - 412.

Duffo-Deno, K.T. and R.W. Eberts (1991), "Public Infrastructure and Regional Economic Development: A Simultaneous Equation Approach", Journal of Urban Economics 30, 329-343.

European Union Financial Reports (2001, 2002), http://europa.eu.int/comm/budget.

Fernald, J.G. (1999), "Roads to Prosperity? Assessing the Link between Public Capital and Productivity”, American Economic Review 89, 619-638.

Heinemann, F. (1999), "Der Kompensationsfonds: Eine neue Finanzverfassung für die EU der 21+”, Wirtschaftsdienst 1999/V, 293 - 299.

Morrison, C.J. and A.E. Schwartz (1996), "State Infrastructure and Productive Performance", American Economic Review 86, 1095-1108.

Munnell, A.H. (1990), "Why Has Productivity Declined? Productivity and Public Investment", New England Economic Review, Federal Reserve Bank of Boston, 3-22.

Munnell, A.H. (1992), "Policy Watch: Infrastructure Investment and Economic Growth", Journal of Economic Perspectives 6, 189-198. 
Nevin, E.T. (1990), "Regional Policy", in: A.M. El-Agraa (ed.), The Economics of the European Community, St. Martin's Press, New York.

Seitz, H. (1995), “The Productivity and Supply of Urban Infrastructures”, Annals of Regional Science 29, 121-141.

Stephan, A. (2001), "Essays on the Contribution of Public Infrastructure to Private Production and its Political Economy”, Dissertation at the Humboldt-University of Berlin, 18-42.

Tatom, J.A. (1991), "Public Capital and Private Sector Performance", Federal Reserve Bank of St. Louis Review, May-June, 3-15

Tondl, G. (2001), "Regional Policy", in: M. Artis and F. Nixson (eds.), The Economics of the European Union, Oxford University Press, Oxford.

Wylie, P.J. (1996), “Infrastructure and Canadian Economic Growth 1946-1991”, Canadian Journal of Economics 29, 350-355. 